\title{
Data exclusivity for biologics
}

\author{
Henry Grabowski, Genia Long and Richard Mortimer
}

As part of the recently enacted health-care reform legislation in the United States, the US Congress authorized an abbreviated regulatory pathway for the approval of biosimilars (also often described as follow-on biologics) ${ }^{1}$. Among other provisions, the legislation grants a new innovative biologic (termed pioneer biologic here) 12 years of data exclusivity, with the potential for an extension of 6 months if paediatric studies are conducted.

Data exclusivity is the length of time before a biosimilar can receive approval from the US Food and Drug Administration by relying at least in part on the safety and efficacy data for the pioneer biologic. Data exclusivity is one factor contributing to market exclusivity - the period of time during which a therapy is the only marketed version of that molecule - but not the only determinant. The results of patent litigation, the time spent in development and regulatory review, commercial decisions by competitors, and other factors all contribute to the market exclusivity period. The appropriate length of the data exclusivity period was widely debated before the abbreviated pathway for biosimilars was enacted; indeed, the US Congress considered bills with periods ranging from 5 years to 14 years. An earlier article intended to help inform this debate developed a financial model to evaluate how

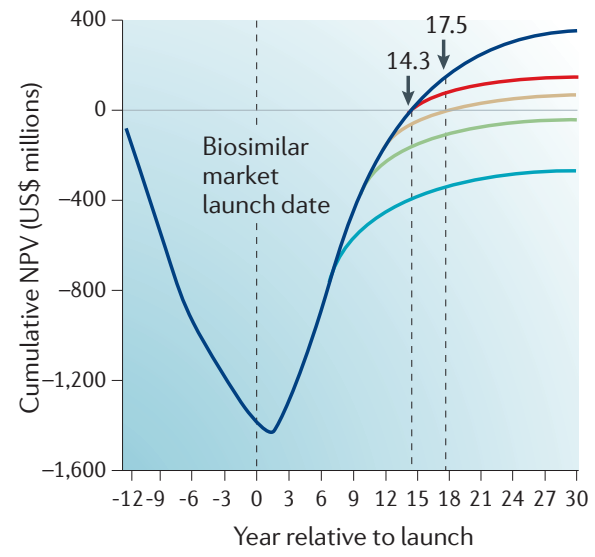

- No biosimilar entry - 10-year market exclusivity

- 7-year market -12-year market exclusivity exclusivity -14-year market exclusivity

Figure 1 | Cumulative net present value (NPV) of cash flows for a representative biologic with various scenarios for market exclusivity. For details of the assumptions, see Supplementary information S1 (box). long a market exclusivity period would be required until a typical pioneer biologic earned a positive investment return ${ }^{2}$. In this model (see Supplementary information S1 (box) for details), a representative portfolio of pioneer biologics would be expected to 'break-even' (or to recover the average costs of development, manufacturing and promotion, and the cost of capital) in 12.9-16.2 years. Here, we present an analysis incorporating two refinements that have been made to this model that directly address important concerns that were raised during the debate leading up to the enactment of the recent US legislation.

\section{Analysis}

Some critics of a 12-year data exclusivity period, including the US Federal Trade Commission in a 2009 report $^{3}$, have argued that 'early mover' competitive advantages should be sufficient to maintain innovation incentives, given relatively few expected biosimilar entrants and the likelihood that biosimilars will not be interchangeable with the pioneer biologic, which is the case with generic small-molecule drugs. To investigate this issue, the original model ${ }^{2}$ has been modified to explicitly incorporate the impact of competition between the pioneer biologic and biosimilars after market exclusivity expires. We examined how substantial retention of sales for the pioneer biologic after biosimilar entry affects the break-even lifetimes for innovators. In addition, the extent to which patents provide protection against the early entry of competitors to a pioneer biologic was also debated. We have therefore conducted a simulation analysis examining interactions between data exclusivity and patent protection (each of which contribute to market exclusivity periods) in different scenarios to highlight the specific circumstances in which each of these modes of protection is important in maintaining innovation incentives.

An analysis of cumulative net present value for a representative pioneer biologic over its life cycle is presented in FIG. 1. This analysis incorporates the research and development (R\&D) and sales information of the representative portfolio of pioneer biologics examined in the previous article ${ }^{2}$. It also incorporates a cost of capital of $12 \%$ and a contribution margin on sales of $50 \%$, consistent
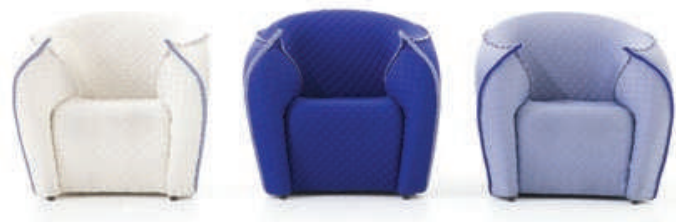

PANNA chair by Tokujin Yoshioka for Moroso. Photographed by Alessandro Paderni

with the earlier study. However, unlike the previous model, the analysis also explicitly models the impact of biosimilar entry on the market share for the pioneer biologic, assuming that the market share for the biosimilar reaches $50 \%$ by year 4 following its entry and price discounts for the pioneer biologic reaching $15 \%$, partially matching biosimilar discounts (Supplementary information S1 (box)). Examining how various market exclusivity periods affect break-even lifetimes, we found that the representative pioneer biologic fails to break-even under both 7-year and 10-year market exclusivity periods, even assuming it retains substantial market share after biosimilar entry. Break-even does occur with 12-year and 14-year market exclusivity periods, taking 17 years and 15 years, respectively. This compares to a break-even period of 14 years in the case of no biosimilar entry.

Although FIG. 1 underscores the impact of at least a 12-year market exclusivity period, it does not distinguish between the contributions of patent protection and data exclusivity in achieving this outcome. After market launch, data exclusivity and patent protection run concurrently. Data exclusivity provides additional market exclusivity protection only to the extent that patents can be circumvented by a biosimilar, or the remaining patent protection is shorter than the data exclusivity at the time of approval of the pioneer biologic.

To distinguish between the effects of these two modes of protection, we conducted a Monte Carlo simulation analysis, in which we defined market exclusivity as the longer of the data exclusivity and patent protection periods. In particular, we considered the effects of the different data exclusivity periods on break-even outcomes under alternative assumptions about patent protection. In scenario 1 (strong patent protection), biologic patents provided a lengthy expected period of protection against biosimilar entry (14 years on average). In scenario 2 (limited patent protection), we assumed only 7 years of expected patent protection, reflecting a lengthy R\&D period or the possibility of successful patent challenges. Our analysis is based on the results of 1,000 Monte Carlo simulations for each scenario and specified data exclusivity period. The simulation draws values from normal distributions of the cost of capital and 


\section{DATA EXCLUSIVITY FOR BIOLOGICS | MARKET INDICATORS}

- contribution margin, as well as the share and price of the pioneer biologic. The mean and standard deviations for these distributions are based on values observed in various empirical analyses (Supplementary information S1 (box)). The sample means are also consistent with the average values underlying the analysis in FIG. 1. The patent protection periods in each scenario are also drawn from a normal distribution to reflect the uncertainty from patent challenges and other events.

The strong patent protection scenario presented in FIG. 2a assumes a mean of 14 years and a standard deviation of 3 years, with $95 \%$ of the draws having a patent protection period between 8 years and 20 years. In this scenario, the data exclusivity period has only a small impact on the likelihood of breaking-even and therefore on investment incentives (that is, patent protection alone is sufficient in most cases to ensure a sufficient market exclusivity period to achieve break-even status). Correspondingly, the data exclusivity period also adds little cost, as it is infrequently binding. The simulation outcomes in FIG. 2a show that patent protection alone (with no data exclusivity period) results in a $70 \%$ likelihood of breaking-even within 25 years of launch. A 12-year data exclusivity period is binding in only $24 \%$ of the draws; increases the average market exclusivity period by less than half a year, from 14.1 years to 14.5 years; and increases the likelihood that a typical biologic portfolio investment will break-even within 25 years from $70 \%$ to $75 \%$.

The limited patent protection scenario presented in FIG. $2 \mathrm{~b}$ assumes a mean of 7 years and a standard deviation of 2.5 years, with $95 \%$ of the draws having a patent protection period between 2 years and 12 years. In this scenario, patent protection alone (with no data exclusivity period) results in only a $14 \%$ likelihood of breaking even within 25 years of launch. A 7-year data exclusivity period is binding in almost $50 \%$ of the draws, but only increases the likelihood of breaking-even within 25 years from $14 \%$ to $17 \%$. A 12 -year data exclusivity period is almost always binding (in $97 \%$ of the draws); increases the average market exclusivity period from 7.1 years (with no data exclusivity period) to 12 years; and increases the likelihood of breaking-even within 25 years from $14 \%$ to $62 \%$, suggesting greatly enhanced incentives for investment.

\section{Policy implications}

The results of this analysis are consistent with the US Congress's determination that a 12-year data exclusivity period for new biologics appropriately balances potential cost savings
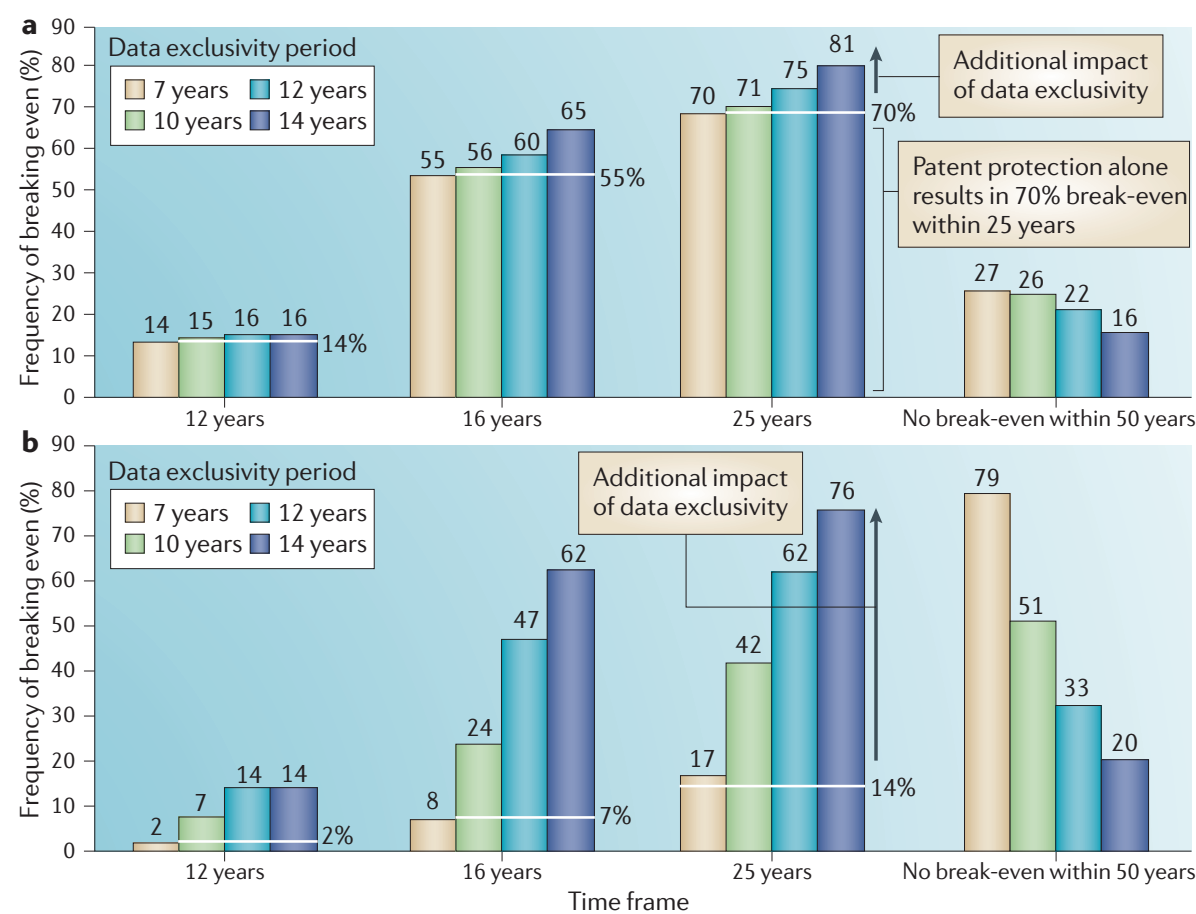

Figure 2 | Influence of data exclusivity and patent protection on break-even points for a representative biologic portfolio. Scenarios in parts $\mathbf{a}$ and $\mathbf{b}$ are based on strong patent protection (average period of 14 years) or limited patent protection (average period of 7 years), respectively. For details of the assumptions, see Supplementary information S1 (box).

from price competition from biosimilars with long-term incentives for investment in innovative biologics. To the degree that biologic patents are relatively less certain and more vulnerable to challenge (our limited patent protection scenario), a data exclusivity period of 12 years greatly enhances investment incentives. Conversely, if biologic patents provide relatively strong protection with significant patent life remaining at approval, patents alone will be sufficient to maintain investment incentives in most cases. In those instances, the data exclusivity period has only a minimal effect on market exclusivity times and thus on health-care costs. The 12-year data exclusivity period therefore operates mainly as an 'insurance policy' to encourage innovation when patent protection is limited.

US data exclusivity periods are now longer for biologics than for new chemical entities (NCEs). Under the Hatch-Waxman legislation, the data exclusivity period is 5 years for NCEs. Patent challenges can be filed after 4 years, but face an additional stay on generic entry of up to 30 months. So, even allowing for a 30-month stay, small molecules with early patent challenges have shorter data exclusivity periods compared to biological entities (that is, 6.5 years versus 12 years). These differences, together with uncertainty on the outcomes of patent challenges early in the life cycle of a product, raise the question of whether future incentives for innovation will be tilted in the direction of biologics. This remains an important issue for further research. It is also notable that the European Union sought to avoid this outcome by harmonizing data exclusivity for both biological entities and chemical entities at 10 years plus an additional year for establishing a clinically important new indication.

\section{Henry Grabowski is at Duke University, Durham, North Carolina 27708, USA. Genia Long and Richard Mortimer are at Analysis Group Inc., Boston, Massachusetts 02199, USA. Correspondence to H.G e-mail:grabow@econ.duke.edu} doi: 10.1038/nrd3277

\footnotetext{
Title VII of the Patient Protection and Affordable Care Act of 2010, Pub. L. No. 111-48, Improving Access to Innovative Medical Therapies-Subtitle (2010).

2. Grabowski, H. Follow-on biologics: data exclusivity and the balance between innovation and competition. Nature Rev Drug Discov. 7, 479-488 (2008).

3. Federal Trade Commission (FTC). Emerging Health Care Issues: Follow-on Biologic Drug Competition. Federal Trade Commission Report | June 2009. FTC website [online], http://www.ftc.gov/os/2009/06/ P083901 biologicsreport.pdf (2009).
}

Competing interests statement

The authors declare no competing financial interests. 


\section{Box S1 | Details of modelling and analysis}

Note 1: summary of assumptions in the previous model. The model incorporates the expected net present values of both the costs and revenues associated with developing innovative biologics to calculate a breakeven period ${ }^{1}$. The break-even period is the period of exclusive marketing required to yield sufficient revenues so that their net present value just offsets the net present value of the costs of development. Alternative financial measures could be calculated, such as the internal rate of return (IRR), which allows for a comparison of the investment return from projected cost and revenue streams to a market rate of return. IRR can be a desirable measure for evaluating investment incentives because it evaluates the overall profitability of an investment; break-even measures are less sensitive to variance in long-term revenue projections as only revenues up to the break-even period affect the calculation while measures of IRR reflect all projected revenues in perpetuity. However, the break-even time period has the advantage in this instance that it offers a more direct interpretation with respect to time period-based policy instruments, such as data exclusivity.

Development costs in the model incorporate the risk of failure by stage, reflecting the fact that most efforts are unsuccessful and innovative firms must invest in a portfolio of projects in order to generate a single marketed product. The cost of capital, the annual rate of return that an investor requires on average to make a given investment, accounts for the time value of money and the long development horizon in which investors incur development costs for many years prior to seeing a return. Revenues are adjusted to reflect an expected contribution margin, a measure of how much a company earns in sales, after subtracting costs for labor and materials, and selling, general and administrative expenses. Because contribution margin does not subtract R\&D costs, they are accounted for separately in the model.

Key assumptions in the previous model ${ }^{1}$ include:

- R\&D costs: calculated from expected costs by stage and risk-adjusted for the expected probability of success by stage, yielding approximately $\$ 500$ million for the clinical and preclinical periods. Capitalized R\&D costs were $\$ 1.24$ billion and $\$ 1.33$ billion, when discounted by cost of capital assumptions of $11.5 \%$ and $12.5 \%$, respectively.

- Sales: calculated based on a stylized portfolio reflecting the top four quintiles of the sales distribution of on-market biologics (excluding the lowest sales quintile). The top four quintiles had average annual peak sales of approximately $\$ 2$ billion, $\$ 500$ million, $\$ 250$ million, and $\$ 100$ million. Sales are assumed to reach peak levels by the 9th year following launch and to decline by $3.5 \%$ annually following the 10th year, due to market factors.

- Cost of capital: $11.5 \%$ and $12.5 \%$ were considered.

- Contribution margin: $50 \%$, based on contribution margins realized by the eight largest biotechnology firms with multiple products on the market.

Using the same R\&D cost and sales assumptions from the previous model, appropriate distributions for assumed biosimilar share, brand price discounts, cost of capital, and contributions margins are considered in the simulation analysis based on a number of published empirical studies. An example of the cumulative net present value calculation is provided in Table S1 below, reflecting the above assumptions and a cost of capital of $11.5 \%$. This example yields a break-even period of 12.9 years. In this example, cumulative net present value (CNPV) is $-\$ 77$ million in year 12 following launch and $\$ 5$ million in year 13 following launch. The break-even period is calculated as the estimated point at which CNPV equals zero. The estimated break-even point of 12.9 years is based on an assumption that CNPV increased linearly between years 12 and 13 .

Note 2: some methodological issues in using historical data as a guide for input values. Our simulation analysis, based on empirically derived data inputs, is designed to determine the levels of patent protection and data exclusivity periods necessary to maintain historical patterns of new product introductions and sales revenues. In this regard, until 2010, biopharmaceutical firms operated in a legal and regulatory environment in which there was 
no abbreviated pathway for biosimiliars to drugs approved under the Public Health Service Act. Accordingly, many firms' investment decisions were formed under the expectation that new product candidates might face no biosimilar competition in the US over their entire product life cycle (even though legislation on an abbreviated pathway has been in the works for several years and firms must project market conditions over several decades). Instead, the primary expected mode of competition was dynamic competition from other biologics with alternative modes of action, new generations of biologics offering additional benefits, or alternative forms of therapy.

Historical benchmarks, therefore, could reflect a state of 'over-investment' in R\&D to some degree from a societal standpoint because of the absence of expected price competition from biosimiliars. An additional countervailing consideration, however, is that many studies indicate there are high societal returns from biopharmaceuticals (with societal returns in excess of private returns), given the large gains in patient welfare from new drug introductions (apart from the returns realized by innovators). These 'spillovers' lead to a potential for countervailing under-investment in $\mathrm{R} \& \mathrm{D}$ from a societal perspective (for example, see REFS 2-4). Grabowski and Wang ${ }^{5}$ showed in an earlier study that new biologics have accounted for a disproportionate number of first-in-class drugs and are targeted to disease indications with high unmet needs such as various cancers, infectious diseases, and various autoimmune diseases such as rheumatoid arthritis. In this paper, we do not take a position on whether there has been a prior under-investment or over-investment in biopharmaceutical R\&D from a societal standpoint. We presume the policy objective the US Congress wanted to reflect in law was a data exclusivity period that would preserve the current level of strong incentives for continued innovation in biologics, and our simulation model can provide insights in this regard.

Note 3: expected biologic price and share competition. The current analysis extends the previous model to consider the impact of biosimilar entry by considering reasonable assumptions with respect to the time path and extent of biosimilar share penetration and any price responses by the manufacturer of the pioneer biologic to biosimilar entry. Theoretical models of competition between innovative biologics and biosimilars suggest more limited biosimilar market shares and price discounts than are observed for small molecules. Grabowski, Ridley and Schulman model the market for biosimilars as reflecting monopolistic competition, and find that the number of biosimilar entrants, biosimilar share penetration, and biosimilar and innovator price discounts will be limited for complex biologics ${ }^{6}$. Chauhan, Towse and Mestre-Ferrandiz model brand-biosimilar competition as facing both pricesensitive and price-insensitive market segments and find that the success of biosimilars will depend on their ability to demonstrate interchangeability (not just similarity) with the brand through clinical trial data and post-launch patient safety evidence ${ }^{7}$. The Chauhan $e t$ al. model results in discounted innovative biologic prices following biosimilar entry, but not to the level of the biosimilar prices.

Over time, markets for biosimilars may evolve to more closely resemble the intensely competitive markets for generic chemical entities ${ }^{8}$, where high-sales products often lose $90 \%$ of the market to generics within a few months ${ }^{9,10}$. Current biologics, however, may be able to earn significant revenues after biosimilar entry. For example, even in the case of chemical entities, Grabowski and colleagues ${ }^{11}$ found that more-complex drugs, which may share many features with biologics, experienced $40 \%$ lower levels of generic share penetration and generic price discounts than less-complex drugs during 1997 to 2003. Similarly, innovative biologics may earn substantial revenues following biosimilar entry, prolonging the innovative product's life beyond the expiration of market exclusivity. Therefore, we investigate the impact of innovator sales and price erosion on the initial breakeven calculations.

To identify reasonable assumptions for innovator biologic price discounts and market share following biosimilar entry, we review evidence from early biosimilar entry in Europe and estimates from the literature. Based on this, we identify appropriate price and share assumptions and incorporate this information into the model.

Biosimilars in Europe. Initial evidence with epoetin alpha (EPO) biosimilar entry in Germany suggests that biosimilars are capturing meaningful market share in some cases. By the end of 2008 , approximately a year following biosimilar entry, almost $50 \%$ of the branded epoetin 
alpha market had transitioned to biosimilars ${ }^{12}$; the price of branded epoetin alpha (Eprex) had declined $16 \%$ over the year; and there was a $25 \%$ price difference between Eprex and the biosimilars (calculations of biosimilar drugs referencing Erypo as a share of those drugs plus Erypo totals $54 \%$ on a standard unit basis as of December 2008). Effects in other biosimilarcountry markets have been smaller.

Price and market share assumptions in the literature. Four recent studies, by the Congressional Budget Office $(\mathrm{CBO})^{13}$ (2008), Avalere Health ${ }^{14}$ (2007), Express Scripts ${ }^{15}$ (2007), and Grabowski and colleagues ${ }^{11}$ (2007), have examined biosimilar penetration and price discounts. Peak biosimilar penetration rate estimates range from $35 \%$ to $60 \%$, with the CBO estimate being the lowest. All of the studies are based on established comparator products that may be imperfect predictors of future biosimilar markets, and most acknowledge that future penetration rates will increase, as was the case with generic penetration following the HatchWaxman legislation, and that expected impacts on products currently in discovery and development will be higher than for today's marketed products.

All of the studies expect biosimilar price discount rates to reach at least $25 \%$, relative to preentry brand price, especially for larger-selling products where more entrants are expected. The one study that provides an estimate of brand price response hypothesizes a 30\% decline in the brand price for large biologics in the third year following biosimilar entry, and a $10 \%$ decline for medium-sized biologics ${ }^{14}$. Table S2 summarizes biosimilar penetration rates and biosimilar and brand price discounts for the four studies and the early EPO experience in Germany.

Cost of capital and contribution margin. Two particularly important assumptions in previous analyses and in our breakeven model are the cost of capital and the contribution margin. The cost of capital is a measure of the financing costs of investment in biologic drug development and launch. Financing costs comprise a substantial portion of the cost of innovative biologic development due to two factors: the high risk of failure in the development stage, which leads investors to require substantial returns for successful biologics; and the long development time, which results in the cost of capital accruing over many years. The contribution margin is the portion of revenue that remains to cover investment costs after netting out production and other associated costs.

Cost of capital. The previous article's estimates of the real cost of capital, $11.5 \%$ and $12.5 \%$, were based on a small sample of large, successful publicly-traded biologic firms, and are slightly below current reliable industry-wide estimates of the cost of capital for biotech R\&D investments. Recent estimates of the real cost of capital for biotechnology firms are no lower than $12.75 \%$, and in some cases much higher when the focus is small- to mid-size biotechnology firms:

Golec and Vernon ${ }^{15}$ estimate a nominal cost of capital of $16.25 \%$, or real cost of capital of $12.75 \%$, for biotech R\&D investment, relying on a three-factor Fama French model. FamaFrench three factor return models are considered to be superior for estimating cost of capital in industries such as biotechnology, and the authors note that the finance literature has established that single-factor return models such as the Capital Asset Pricing Model (CAPM) do not capture all of the types of systematic risk that influence firm cost of capital, in particular, CAPM does not capture systematic size and book-to-market risk factors.

Ibbotson's Cost of Capital Yearbooks, a widely accepted general industry source, report similar nominal three-factor Fama-French estimates for 2006 to 2008, in the range of $17.01 \%$ to $17.68 \%$ for the median publicly-traded company in SIC code 2836 (biotechnology). Assuming 3\% annual inflation, this corresponds to a $13.60 \%$ to $14.25 \%$ real cost of capital. Ibbotson's Cost of Capital 2009 Yearbook reports substantially lower estimates $(13.20 \%$ nominal and $9.90 \%$ real cost of capital), given market developments over the past year.

Cockburn and Lerner ${ }^{17}$, Grossman ${ }^{18}$ and Myers and Shyum-Sunder ${ }^{19}$ find substantially higher cost of capital estimates for small biotechnology firms and venture capital investments, ranging from nominal rates of $18 \%$ to $27.4 \%$ (real cost of capital of $14 \%$ to $23.7 \%$ ). Assuming $3 \%$ annual inflation, these figures correspond to real costs of capital of $23.7 \%$ and $15.2 \%$, respectively. 
Consistent with these findings, many small biotechnology firms rely heavily on venture capital financing, which typically implies a very high cost of capital, and may face difficulties obtaining financing when macro-level credit supply contracts. Table S3 summarizes biotechnology industry cost of capital figures from a wide range of sources.

Contribution margin. The previous article ${ }^{1}$ assumed a 50\% contribution margin. However, few biotech companies are profitable, and there are many development-stage companies whose principal assets are their human capital and intellectual property. These companies experience lower contribution margins than firms with established lines of approved products as represented by the sample that reflects even a 50\% margin. Table S4 provides contribution margins for eight large public biotech companies for the period 2001 to 2007, ranging from $34 \%$ to $64 \%$.

Note 4: summary of input assumptions in the current break-even model. The current model incorporates the same method of evaluating expected net present values of both the costs and revenues of developing new biologics to calculate a breakeven period. Assumptions with respect to nominal $\mathrm{R} \& \mathrm{D}$ costs and sales are the same as those used in the previous model ${ }^{1}$. The analyses rely on several additional assumptions related to brand price discounts and biosimilar share following biosimilar entry, as well as cost of capital and contribution margins. Figure 1 relies only on the mean assumption for each of these categories, while Figures $2 \mathrm{a}$ and $2 \mathrm{~b}$ rely on the assumed distribution of possible values for each category. The mean and standard deviations for these distributions are based on the literature and observations. The assumptions include:

- Brand price discount by the fourth year following biosimilar entry is normally distributed with a mean of $15 \%$ and a standard deviation of $7.5 \%$, with $95 \%$ of the draws from the distribution between approximately $0 \%$ and $30 \%$. Table S2 provides a summary of the limited evidence available on brand price discounts for biologics. The mean brand price discount and 95\% range assumed here are consistent with the early Eprex experience in Germany (16\% discount after one year) and the Avalere Health (2007) study, which assumes that brand prices will decline $30 \%$ for large biologics and $10 \%$ for medium biologics by the third year after biosimilar entry. The price discount is assumed to increase linearly from the first to the fourth year after biosimilar entry.

- Biosimilar share by the fourth year following biosimilar entry is calculated based on the brand price discount. We assume that higher draws of brand price discounts are associated with lower levels of biosimilar share. Specifically, we calculate:

$$
\text { Biosimilar share }=65 \%-\text { brand price discount }+\varepsilon
$$

where $\varepsilon$ is distributed with mean 0 and standard deviation $2.5 \%$. On average, biosimilar share is equal to $50 \%$ in our simulations, and for $95 \%$ of the simulations takes a value between $35 \%$ and $65 \%$. Table S2 also provides a summary of the evidence available on biosimilar share. The mean biosimilar share and the 95\% range are consistent with the early Eprex experience in Germany and the estimates proposed by Avalere Health ${ }^{14}$. The biosimilar share is assumed to increase linearly from the first to the fourth year after biosimilar entry.

- Cost of capital is normally distributed with a mean of $12 \%$ and a standard deviation of $0.5 \%$, with $95 \%$ of the draws from the distribution between approximately $11 \%$ and $13 \%$. Table S3 provides a summary of evidence from the literature and other sources supporting a real cost of capital estimate in the range of $11 \%$ to $13 \%$ for biologic companies. In particular, this range captures the $11.5 \%$ and $12.5 \%$ estimates from Grabowski (2007), and the $12.75 \%$ estimate from Golec and Vernon ${ }^{16}$. The upper end of the range is somewhat lower than the Ibbotson real median three-factor Fama-French measures for 2006 to 2008, while the lower end of the range is somewhat higher than the Ibbotson measure for 2009.

- Contribution margin is normally distributed with a mean of $50 \%$ and a standard deviation of $5 \%$, with $95 \%$ of the draws from the distribution between approximately $40 \%$ and 
$60 \%$. This is consistent with the range of contribution margins of large biotech companies in Table S4.

Note 5: cost of capital assumption and investment in early-stage innovation. Optimal data exclusivity periods depend not only on industry aggregate analyses (as presented here), but also on the effects on early-stage innovators who account for many of the new pipeline biologics. Unlike established public biotech companies, early-stage innovators are typically privately held and rely on private risk capital financing, such as venture capital. It has been estimated that venture capital-backed firms constitute $40 \%$ of employment in biotechnology ${ }^{20}$. Such firms use discount rates that vary by stage of investment, with a decreasing level of risk as products approach launch and commercialization. An empirical analysis found that discount rates vary from $70 \%$ down to $25 \%$, depending on stage of finance (start-ups to IPOs) $)^{21}$. A recent study by Cockburn and Lerner ${ }^{17}$ estimates costs of capital of $18.5 \%$ for smallcap, early-stage biotech companies and $21 \%$ for venture investment in biotech. The cost of capital estimates relied on in the previous sections reflect only publicly-traded biotech companies, and do not capture the higher implied cost of capital for early-stage innovators.

The relatively high cost of capital for early-stage innovators suggests that data exclusivity periods sufficient to maintain investment incentives in medium and large public biotech companies may be too low to support investment in early-stage innovators. The high cost of capital for early-stage innovators may be partially offset by lower R\&D costs, as R\&D may be directed more toward preclinical or earlier-phase research. However, the high sensitivity of investment incentive to higher cost of capital and the importance of early-stage investment to the development of new biologics highlight the importance of setting data exclusivity periods with the objective of maintaining early-stage innovation incentives. If incentives are insufficient to promote the development of 'seed corn', early-stage leads will never advance into later-stage development opportunities.

\section{References}

1. Grabowski, H. Follow-on biologics: data exclusivity and the balance between innovation and competition. Nature Rev. Drug Discov. 7, 479-488 (2008).

2. Mansfield, E., Rapoport, J., Romeo, A., Wagner, S. \& Beardsley, G. Societal and private rates of return from industrial innovations. Q. J. Econ. 91, 221-240 (1997).

3. Griliches, Z. Issues in assessing the contribution of research and development to productivity growth. Bell J. Econ. 10, 92-116 (1979).

4. Cutler, D. \& McClellan, M. Is technology change in medicine worth it? Health Affairs 20, 11-29 (2001).

5. Grabowski, H. \& Wang, Y. R.. The Quality and Quantity of Worldwide New Drugs Direction 1992-2003. Health Affairs .25, 452-460 (2006).

6. Grabowski, H., Ridley, D. \& Schulmann, K. Entry and competition in generic biologics. Manag.Decis. Econ. 28, 4-5 (2007).

7. Chauhan, D, Towse, A \& Mestre-Ferrandiz, J. The market for biosimilars: evolution and policy options. (OHE Briefing 45, OHE, London, October 2008).

8. Grabowski, H., Cockburn, I. \& Long, G. The market for follow-on biologics: how will it evolve? Health Affairs 25, 1291 - 1301 (2006).

9. Grabowski, H. Are the economics of pharmaceutical R\&D changing? Productivity, patents and political pressures. Pharmcoeconomics 22 (Suppl. 2), 15-24 (2004).

10. Silver, R. A Wall street perspective on generics.

[online], $<$ http://www.gphaonline.org/AM/CM/ContentDisplay.cfm?ContentFileID=593 > (2007).

11. Grabowski, H., Cockburn, I., Long, G., Mortimer, R. \& Johnson, S. The effect on federal spending of legislation creating a regulatory framework for follow-on biologics: key issues and assumptions. Duke University Department of Economics White Paper. [online], $<$ http://www.econ.duke.edu/Papers/PDF/0907_H_Grabowski_I_Cockburn_G_Long_et_al_E ffect_on_Federal_Spending_of_Follow_on_Biologics.pdf> (2007).

12. Hospira responses to FTC questions on biosimilars. [online],

$<$ http://www.ftc.gov/os/comments/healthcarecompissues/090519hospirasupplementonbiosim ilars.pdf $>$ (2009). 
13. Congressional Budget Office, Cost Estimate: S.1695 Biologics Price Competition and Innovation Act of 2007, June 25, 2008.

14 Ahlstrom, A. et al. Modeling federal cost savings from follow-on biologics. Avalere Health White Paper. [online],

$<$ http://www.avalerehealth.net/research/docs/Modeling_Budgetary_Impact_of_FOBs.pdf $>$ (2007).

15. Miller, S. \& Houts, J. Potential savings of biogenerics in the United States. (Express Scripts, February 2007).

16. Golec, J. \& Vernon, J. Financial risk in the biotechnology industry versus the pharmaceutical industry. Appl. Health Econ. Health Policy 7, 155-165 (2009).

17. Cockburn, I. \& Lerner, J. The cost of capital for early-stage biotechnology ventures. [online],

$<$ http://www.nvca.org/index.php?option=com docman\&task=doc download\&gid=465\&Ite mid $=93>(2009)$.

18. Grossmann, M. Entrepreneurship in Biotechnology (Physica-Verlag, New York 2003).

19. Myers, S., and Shyum-Sunder, L. Measuring pharmaceutical industry risk and the cost-of-capital. in Competitive Strategies in the Pharmaceutical Industry (ed. Helms, R. B.) 208 - 237 (AEI Press, Washington, DC, 1996).

20. Burns, L. R., Housman, M. G. \& Robinson, C. A. Market entry and exit by biotech and device companies funded by venture capital. Health Affairs. 28, w76-w86 (2009).

21. Sahlman, W. A. The structure and governance of venture-capital organizations. $J$. Finan. Econ. 27, 47 -521 1990). 
Table S1 | Example break-even period calculation (values in \$ millions)

\begin{tabular}{|c|c|c|c|c|c|c|c|}
\hline $\begin{array}{l}\text { Time to } \\
\text { launch }\end{array}$ & $\begin{array}{l}\text { Fixed costs } \\
\text { R\&D, } \\
\text { launch, } \\
\text { and plant } \\
\quad[\mathrm{A}]\end{array}$ & $\begin{array}{l}\text { Revenue } \\
\text { Sales } \\
\text { [B] }\end{array}$ & $\begin{array}{l}\text { Variable costs } \\
\text { COGS, SG\&A } \\
\text { and post-launch } \\
\text { R\&D } \\
\quad[\mathrm{C}]\end{array}$ & $\begin{array}{l}\text { Profitability } \\
\text { Profit } \\
{[\mathrm{D}]=[\mathrm{B}]-} \\
{[\mathrm{A}]-[\mathrm{C}]}\end{array}$ & $\begin{array}{l}\text { Presen } \\
\text { Discount } \\
\text { factor }{ }^{\star} \\
{[E]}\end{array}$ & $\begin{array}{l}\mathrm{NPV} \\
\qquad[\mathrm{F}]=[\mathrm{D}]^{*}[\mathrm{E}]\end{array}$ & $\begin{array}{l}\text { CNPV } \\
\text { Sum } \\
{[\mathrm{F}]}\end{array}$ \\
\hline-12 & $\$ 22$ & & & $\$-22$ & 3.90 & $-\$ 85$ & $-\$ 85$ \\
\hline-11 & 46 & & & -46 & 3.50 & -160 & -244 \\
\hline-10 & 46 & & & -46 & 3.14 & -143 & -388 \\
\hline-9 & 46 & & & -46 & 2.81 & -129 & -516 \\
\hline-8 & 49 & & & -49 & 2.52 & -123 & -639 \\
\hline-7 & 66 & & & -66 & 2.26 & -149 & -788 \\
\hline-6 & 54 & & & -54 & 2.03 & -110 & -898 \\
\hline-5 & 43 & & & -43 & 1.82 & -78 & -976 \\
\hline-4 & 44 & & & -44 & 1.63 & -72 & -1047 \\
\hline-3 & 55 & & & -55 & 1.46 & -80 & -1128 \\
\hline-2 & 55 & & & -55 & 1.31 & -72 & -1200 \\
\hline-1 & 62 & & & -62 & 1.18 & -73 & -1272 \\
\hline 0 & 38 & & & -38 & 1.06 & -40 & -1313 \\
\hline 1 & & $\$ 128$ & $\$ 191$ & -63 & 0.95 & -60 & -1372 \\
\hline 2 & & 243 & 243 & 24 & 0.85 & 20 & -1352 \\
\hline 3 & & 328 & 213 & 139 & 0.76 & 106 & -1246 \\
\hline 4 & & 413 & 256 & 182 & 0.68 & 124 & -1121 \\
\hline 5 & & 506 & 302 & 228 & 0.61 & 140 & -981 \\
\hline 6 & & 577 & 338 & 264 & 0.55 & 145 & -836 \\
\hline 7 & & 648 & 373 & 299 & 0.49 & 148 & -689 \\
\hline 8 & & 676 & 387 & 313 & 0.44 & 139 & -550 \\
\hline 9 & & 713 & 357 & 357 & 0.40 & 141 & -409 \\
\hline 10 & & 713 & 357 & 357 & 0.36 & 127 & -282 \\
\hline 11 & & 688 & 344 & 344 & 0.32 & 110 & -172 \\
\hline 12 & & 664 & 332 & 332 & 0.29 & 95 & -77 \\
\hline 13 & & 641 & 320 & 320 & 0.26 & 82 & 5 \\
\hline 14 & & 618 & 309 & 309 & 0.23 & 71 & 76 \\
\hline 15 & & 597 & 298 & 298 & 0.21 & 62 & 138 \\
\hline 16 & & 576 & 288 & 288 & 0.19 & 53 & 191 \\
\hline 17 & & 556 & 278 & 278 & 0.17 & 46 & 237 \\
\hline 18 & & 536 & 268 & 268 & 0.15 & 40 & 277 \\
\hline 19 & & 517 & 259 & 259 & 0.13 & 35 & 311 \\
\hline 20 & & 499 & 250 & 250 & 0.12 & 30 & 341 \\
\hline
\end{tabular}

${ }^{\star}$ Discount factor $=\frac{1}{(1+r)^{(t-0.5)}}$ where $\mathrm{r}$ is the cost of capital and $\mathrm{t}$ is the time to launch. Break-even occurs when cumulative net present value $(\mathrm{CNPV})$ equals zero. Cost of capital $=$ $11.5 \%$; contribution margin $=50 \%$ by year 3 . 
Table S2 | Biosimilar competition: market share and price discount evidence

\begin{tabular}{|c|c|c|c|}
\hline Source ${ }^{11-15}$ & $\begin{array}{l}\text { Peak biosimilar } \\
\text { penetration rate }\end{array}$ & $\begin{array}{l}\text { Brand price discount } \\
\text { (relative to pre-entry brand } \\
\text { price) }\end{array}$ & Basis \\
\hline $\begin{array}{l}\text { Biosimilar EPO in } \\
\text { Germany }\end{array}$ & $50 \%($ year 1$)$ & $16 \%$ (year 1) & $\begin{array}{l}\text { Experience of biosimilar EPO in } \\
\text { Germany }\end{array}$ \\
\hline CBO (2008) & $\begin{array}{l}10 \% \text { (year } 1 \text { ) to } 35 \% \text { (year } \\
4 \text { ) }\end{array}$ & & Similar market situations \\
\hline $\begin{array}{l}\text { Grabowski et al. } \\
(2007)\end{array}$ & $10-45 \%$ & & $\begin{array}{l}\text { Higher estimates correspond to } \\
\text { complex small molecules }\end{array}$ \\
\hline Express Scripts (2007) & $49 \%$ & & Therapeutic alternatives \\
\hline $\begin{array}{l}\text { Avalere Health } \\
(2007)^{\star}\end{array}$ & $60 \%{ }^{*}$ & $\begin{array}{l}10 \% \text { to } 30 \% \text { (year } 3 \text { ) } \\
\text { depending on size of market } \\
\text { for the biologic }\end{array}$ & $\begin{array}{l}\text { Average small-molecule generic } \\
\text { drug penetration rates }\end{array}$ \\
\hline
\end{tabular}

${ }^{\star}$ Biosimilar penetration estimates are for the largest selling products. Avalere Health is conducting further analysis.

Table S3 | Cost-of-capital estimates for the biotechnology industry

\begin{tabular}{|c|c|c|c|c|}
\hline \multirow[b]{2}{*}{ Source } & \multirow[b]{2}{*}{ Sector/group } & \multirow[b]{2}{*}{ Model } & \multicolumn{2}{|c|}{ Cost of capital } \\
\hline & & & Nominal & Real \\
\hline Golec \& Vernon (2009) & Biotech industry-wide & Fama-French & $16.25 \%$ & $12.75 \%$ \\
\hline Ibbotson (2006) [1] & Median & Fama-French & $17.68 \%$ & $14.25 \%$ \\
\hline Ibbotson (2007) & Median & Fama-French & $17.01 \%$ & $13.60 \%$ \\
\hline Ibbotson (2008) & Median & Fama-French & $17.49 \%$ & $14.07 \%$ \\
\hline Ibbotson (2009) & Median & Fama-French & $13.20 \%$ & $9.90 \%$ \\
\hline \multirow[t]{3}{*}{ Grossman (2003) [2] } & $\begin{array}{l}\text { Large drug companies } \\
\text { Biotech with } \geq 1 \text { drug }\end{array}$ & CAPM & $15.70 \%$ & $12.33 \%$ \\
\hline & $\begin{array}{l}\text { approved } \\
\quad \text { Biotech drugs in phase II or }\end{array}$ & CAPM & $18.70 \%$ & $15.24 \%$ \\
\hline & III trials & CAPM & $27.40 \%$ & $23.69 \%$ \\
\hline \multirow{2}{*}{$\begin{array}{l}\text { Myers and Shyam-Sunder } \\
\text { (1995) }\end{array}$} & $\begin{array}{l}\text { Medium-sized publicly } \\
\text { traded }\end{array}$ & CAPM & $19 \%$ & $14 \%$ \\
\hline & Small firms & CAPM & & $16 \%$ \\
\hline \multirow[t]{2}{*}{ Cockburn \& Lerner (2009) } & Small firms & CAPM & $18 \%$ & $14.56 \%$ \\
\hline & Venture investment & CAPM & $21.50 \%$ & $17.96 \%$ \\
\hline Grabowski (2008) [3] & Biotech industry-wide & CAPM & & $11.5 \%-12.5 \%$ \\
\hline
\end{tabular}

Grey cells indicates calculated estimates of real cost of capital based on reported nominal values and assuming a 3\% annual inflation rate.

[1] The reported number is for the WACC; Ibbotson includes 78, 75, 73, and 69 firms in SIC 2836 in 2006, 2007, 2008, and 2009 respectively.

[2] Grossman (2003) relies on a nominal risk free rate of $6.8 \%$ and a risk premium of $8.6 \%$.

[3] Grabowski (2008) estimates are based on DiMasi and Grabowski (2007). 
Table S4 | Contribution margins for large biotechnology companies: 2001 to 2007

\begin{tabular}{lll}
\hline Company & Average margin [1] & Comments \\
\hline Gilead Sciences Inc [2] & $63.7 \%$ & Substantial small-molecule drug sales \\
\hline Genentech Inc & $63.3 \%$ & \\
\hline Amgen Inc [3] & $60.4 \%$ & Substantial small-molecule drug sales \\
\hline Celgene Corp [2] & $50.0 \%$ & \\
\hline Genzyme Corp & $44.4 \%$ & \\
\hline Biogen Idec Corp [4] & $43.4 \%$ & \\
\hline Chiron Corp [5] & $35.8 \%$ & \\
\hline MedImmune Inc [6] & $33.6 \%$ & \\
\hline
\end{tabular}

Sources: Bloomberg and SEC 10-K filings.

Notes:

[1] The average contribution margin for each company over the seven year period was calculated as the ratio of total product and royalty revenue less total cost of sales less total SG\&A, to total product and royalty revenue. This may overstate profitability as it includes royalty payments (e.g., from foreign partners) without an allocation of production costs.

[2] Gilead and Celgene have substantial small-molecule drug sales and their margins in part reflect the higher margins associated with small-molecule drugs.

[3] Amgen Inc does not report royalties as a separate line item on its 10-Ks for 2004-2007. Instead, 'other revenues' are reported, where "other revenues consist of royalty income and corporate partner revenues." As a result, contribution margin may be slightly overstated compared to the method used for the other companies.

[4] The calculation for Biogen Idec Corp uses Biogen Corp data for 2001 and 2002.

[5] Chiron Corp average margin based on 10-Ks from 2001-2005, prior to being acquired by Novartis.

[6] MedImmune average margin based on 10-Ks from 2001-2006, prior to being acquired by AstraZeneca. 